Check for updates

Cite this: RSC Adv., 2022, 12, 7605

\title{
Reversible ammonia uptake at room temperature in a robust and tunable metal-organic framework $\dagger$
}

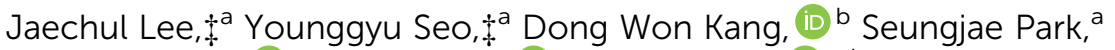 \\ Hyunyong Kim, (D) a Jaheon Kim, (D) Kimoon Kim, (D) ade Chang Seop Hong, (D)*b \\ Dae-Woon Lim* ${ }^{* f g}$ and Eunsung Lee (iD)*ad
}

Received 25th February 2022

Accepted 3rd March 2022

Ammonia is useful for the production of fertilizers and chemicals for modern technology, but its high toxicity and corrosiveness are harmful to the environment and human health. Here, we report the recyclable and tunable ammonia adsorption using a robust imidazolium-based MOF (JCM-1) that uptakes $5.7 \mathrm{mmol} \mathrm{g}^{-1}$ of $\mathrm{NH}_{3}$ at $298 \mathrm{~K}$ reversibly without structural deformation. Furthermore, a simple substitution of $\mathrm{NO}_{3}^{-}$with $\mathrm{Cl}^{-}$in a post-synthetic manner leads to an increase in the $\mathrm{NH}_{3}$ uptake capacity of $\mathrm{JCM}-1\left(\mathrm{Cl}^{-}\right)$up to $7.2 \mathrm{mmol} \mathrm{g}^{-1}$

rsc.li/rsc-advances

\section{Introduction}

Ammonia is one of the essential chemicals not only for fertilizers in agriculture but also for various industrial applications such as an alternative fuel, refrigerants, and a precursor for numerous nitrogenous compounds. As the second mostproduced chemical in the world, over 150 million tons of ammonia is annually produced. ${ }^{1}$ Such a huge production and extensive usage of $\mathrm{NH}_{3}$ raises concerns about the environment and human health issues because of its toxic and corrosive properties. The United States Department of Labor alerts that exposure only to a small amount of ammonia can damage a human body. In the atmosphere, $\mathrm{NH}_{3}$ can combine with sulfate and nitrate to form fine particulate matter (PM2.5), causing severe particulate air pollution..$^{2-4}$ In this context, practical methods and materials for the removal of ammonia emitted in the air are highly desirable.

${ }^{a}$ Department of Chemistry, Pohang University of Science and Technology (POSTECH), Pohang, 37673, Republic of Korea. E-mail: eslee@postech.ac.kr

${ }^{b}$ Department of Chemistry, Korea University, Seoul 02841, Republic of Korea. E-mail: cshong@korea.ac.kr

'Department of Chemistry, Soongsil University, Seoul 06978, Republic of Korea

${ }^{d}$ Division of Advanced Materials Science, Pohang University of Science and Technology, Pohang 37673, Republic of Korea

${ }^{e}$ Center for Self-assembly and Complexity, Institute for Basic Science (IBS), Pohang, 37673, Republic of Korea

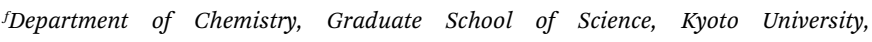
Kitashirakawa Oiwakecho, Sakyo-ku, Kyoto 606-8502, Japan

${ }^{g}$ Department of Chemistry and Medical Chemistry, Yonsei University, Wonju, 26493, Republic of Korea. E-mail: limdaewoon@yonsei.ac.kr

$\dagger$ Electronic supplementary information (ESI) available. CCDC 1912377. For ESI and crystallographic data in CIF or other electronic format see DOI: $10.1039 / \mathrm{d} 2 \mathrm{ra} 01270 \mathrm{~g}$

$\ddagger$ These authors contribute equally.
Metal-organic frameworks (MOFs) have emerged as a promising material for the capture of toxic chemicals such as $\mathrm{NH}_{3},{ }^{5-19}$ $\mathrm{NO}_{x}{ }^{20-23} \mathrm{SO}_{x},{ }^{24-26}$ and volatile organic compounds ${ }^{27,28}$ because well-ordered porosity with feasible chemical and structural tunability of pore surfaces enables such applications. Synthesis of MOFs with high structural stability toward corrosive species is a critical issue for real-world applications. In this regard, several MOFs that can take up $\mathrm{NH}_{3}$ under atmospheric condition has been developed recently. ${ }^{5-19,29}$ Nevertheless, structural instability of adsorbent and high regeneration temperature are still remaining challenges for practical applications., ${ }^{5,-19}$ MOFs showing recyclable ammonia adsorption while retaining its porosity are still very rare. The limited stability of MOFs under ammonia conditions is ascribed to the coordinating nature of $\mathrm{NH}_{3}$. That is, $\mathrm{NH}_{3}$ as a good sigma donating ligand can replace the existing ligand in MOFs, leading to framework decomposition. ${ }^{30}$ Next, strong $\mathrm{NH}_{3} \cdots$ MOF interactions through open metal sites or acid-base interactions necessitate high regeneration temperature, which in turn needs high thermal stability of MOFs and energy-intensive regeneration processes as well. Thus far, MFM-300(Al) reported by M. Schröder and co-workers in 2018 is a representative MOF that can repeatedly adsorb ammonia with regeneration at room temperature..$^{29}$ In addition, there have been reported numerous examples for uptaking ammonia using MOFs for the past five years (Table S3 $\dagger$ ). Nevertheless, it is still challenging to devise robust MOFs that enables reversible uptake of ammonia under mild regeneration conditions.

Recently, we reported a microporous MOF, JCM-1 ([Co(PzIm) $\left.\left(\mathrm{NO}_{3}\right)\right], \mathrm{H}_{2}$ PzIm $=$ 1,3-bis(3,5-dimethyl-1 $H$-pyrazol-4yl)-imidazolium). ${ }^{31}$ JCM-1 has a cationic three-dimensional framework formed by $\mathrm{Co}(\mathrm{II})$-pyrazolate coordination bonds, where imidazolium groups are aligned along the channels containing $\mathrm{NO}_{3}{ }^{-}$ions (Fig. S1 $\dagger$ ). Since azolates such as 
pyrazolate, imidazolate, and triazolate have a greater Lewis basicity than common carboxylates, MOFs constructed from azolate linkers are well-known to possess superior durability against polar solvent. ${ }^{32-34}$ Indeed, JCM-1 has outstanding properties such as high hydrolytic stability, a unique pore structure, and gas separation abilities. ${ }^{31}$ For its unique gas sorption properties, the imidazolium functionality in JCM-1 plays a crucial role as a mimic of ionic liquid solutions. We also found that some imidazolium-based ionic liquids show high ammonia solubility by weak hydrogen bonds between imidazolium salt and $\mathrm{NH}_{3} \cdot{ }^{35-38}$ Studies on the $\mathrm{NH}_{3}$ adsorption using imidazolium-based MOFs have not been reported so far, which motivated us to investigate the $\mathrm{NH}_{3}$ capture ability of JCM-1 (Fig. 1).

\section{Results and discussion}

\section{Synthesis and characterization of JCM-1 and JCM-1(Cl $\left.{ }^{-}\right)$}

Herein, we report the recyclable and tunable ammonia adsorption using JCM-1, which is the first demonstration of $\mathrm{NH}_{3}$ capture utilizing an imidazolium-based MOF. JCM-1 was synthesized according to the previous procedure by heating a mixture of $\mathrm{Co}\left(\mathrm{NO}_{3}\right)_{2}\left(\mathrm{H}_{2} \mathrm{O}\right)_{6}$ and the $\mathrm{H}_{2} \mathrm{PzImCl}$ ligand in $\mathrm{N}, \mathrm{N}$ dimethylformamide (details in the ESI $\dagger$ ). In the single-crystal Xray structure of JCM-1, one-dimensional channels are running through the [001] direction with an aperture size of $12.5 \times 3.9 \AA$. The nitrate anion in the channels of JCM-1 can be fully replaced by chloride ion to obtain $\mathbf{J C M - 1}\left(\mathbf{C l}^{-}\right)$by post-synthetic anion exchange method following the previous procedures. The crystal structure of JCM-1 $\left(\mathbf{C l}^{-}\right)$by single-crystal X-ray diffraction analysis showed that the space group of $\mathbf{J C M - 1}\left(\mathbf{C l}^{-}\right)$was not changed $\left(I 4_{1} /\right.$ amd $)$ with almost the same unit cell parameters as JCM-1 (Fig. S2 and Table S1†); the cationic scaffold remained unchanged, and only the anion species in the pore was replaced after ion substitution. When the crystals of JCM-1 were treated with $1 \mathrm{M}$ ammonia solution in THF for 24 hours (Fig. 2a), the crystals remained intact, which secures the chemical stability of JCM-1 toward corrosive ammonia, enabling $\mathrm{NH}_{3}$ gas uptake measurements.

The total $\mathrm{NH}_{3}$ uptake amounts of JCM-1 at 1 bar were 7.9 and $5.7 \mathrm{mmol} \mathrm{g}^{-1}$ at $273 \mathrm{~K}$ and $298 \mathrm{~K}$, respectively (Fig. 2b), which are comparable with other $\mathrm{NH}_{3}$ adsorbing MOFs. ${ }^{5-19,29}$ Notably, JCM-1 surpasses other materials in terms of framework stability upon regeneration, which are the critical properties of energy-

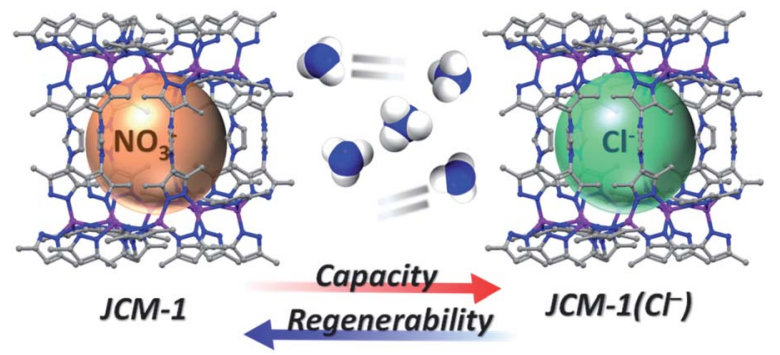

Fig. 1 Schematic illustration of ammonia adsorption with JCM-1 and $\mathrm{JCM}-1\left(\mathrm{Cl}^{-}\right)$.
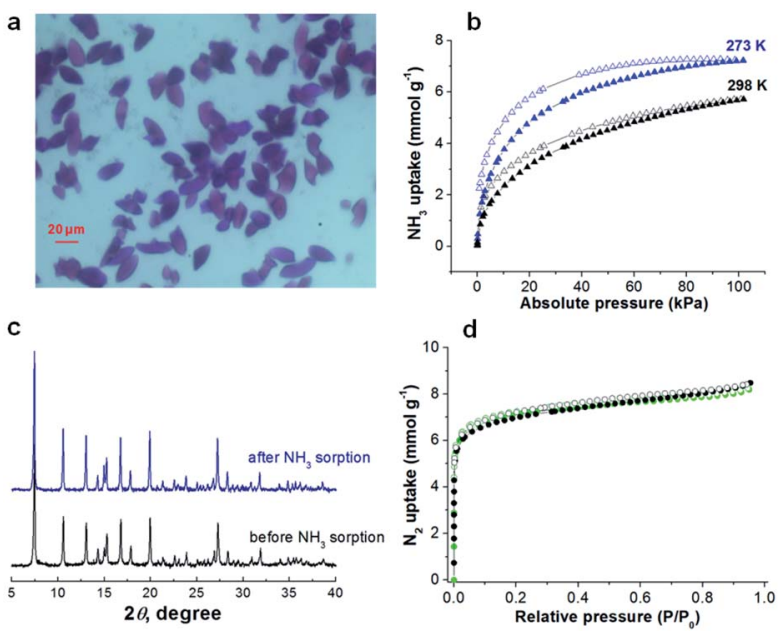

Fig. 2 (a) A picture for the crystals of JCM-1 stored in $1 \mathrm{M}$ ammonia THF solution at room temperature for 24 hours. (b) $\mathrm{NH}_{3}$ adsorption isotherms of JCM-1 at $273 \mathrm{~K}$ and $298 \mathrm{~K}$. (c) PXRD patterns and (d) $\mathrm{N}_{2}$ adsorption isotherms of $\mathrm{JCM}-1$ before and after ammonia adsorption experiments (black circle, before $\mathrm{NH}_{3}$ sorption; light-green circle, after $\mathrm{NH}_{3}$ sorption).

efficient $\mathrm{NH}_{3}$ adsorbent materials. Although a substantial number of MOFs were tested for ammonia adsorption thus far, they suffer from structural deformation after exposure to corrosive $\mathrm{NH}_{3}$ gas. ${ }^{5,7-19,39,41}$ Many of the MOFs show decreased porosity with the degradation of crystallinity during repeated $\mathrm{NH}_{3}$ adsorption-desorption processes, resulting in peak broadening in powder X-ray diffraction (PXRD) patterns. In contrast, JCM-1 could maintain the initial crystallinity and the porosity after $\mathrm{NH}_{3}$ adsorption experiments, which was confirmed by the almost unchanged PXRD patterns and $\mathrm{N}_{2}$ sorption isotherms (Fig. 2c and d).

\section{Ammonia adsorption of JCM-1 and JCM-1 $\left(\mathrm{Cl}^{-}\right)$}

Unlike other MOFs capturing ammonia, JCM-1 has no open metal sites and no acid functional groups for strong interaction with $\mathrm{NH}_{3}$. Instead, it possesses imidazolium functional groups on the pore surfaces to form weak hydrogen bonds with $\mathrm{NH}_{3}$.

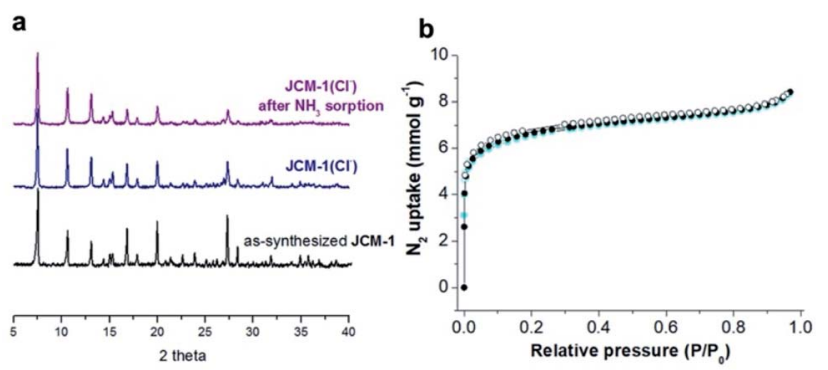

Fig. 3 (a) PXRD patterns of as-synthesized JCM-1, JCM-1(Cl- ) before $\mathrm{NH}_{3}$ adsorption, and $\mathrm{JCM}-1\left(\mathrm{Cl}^{-}\right)$after $\mathrm{NH}_{3}$ adsorption experiment. (b) $\mathrm{N}_{2}$ adsorption isotherms of $\mathrm{JCM}-1\left(\mathrm{Cl}^{-}\right)$before and after ammonia adsorption experiments (black circle: before $\mathrm{NH}_{3}$ sorption, cyan circle: after $\mathrm{NH}_{3}$ sorption). 
The imidazolium protons and counter anions in JCM-1 can act respectively as a proton donor and a proton acceptor, enabling cooperative hydrogen bonding with $\mathrm{NH}_{3}$. This weak but effective intermolecular interaction seems to facilitate the reactivation of JCM-1 after repeated $\mathrm{NH}_{3}$ adsorption measurements. We carried out cycle experiments (Fig. 4a and c), and observed that the sample could be fully evacuated at room temperature under dynamic vacuum. The $\mathrm{NH}_{3}$ uptake capacity was well retained over five cycles, showing the facile regenerability of JCM-1 under mild conditions.

The $\mathrm{NH}_{3}$ uptake capacity and sorption affinity of JCM-1 could be also modulated by replacing $\mathrm{NO}_{3}{ }^{-}$with $\mathrm{Cl}^{-}$in a postsynthetic manner, where JCM-1 was soaked in a methanol solution of LiCl for a week to give anion-exchanged JCM-1 $\left(\mathbf{C l}^{-}\right)$. Although the effectiveness of anion inserted into a MOF for modulating ammonia uptake was reported by Binaeian, ${ }^{15}$ the exchange of counter anions in the cationic framework was investigated for ammonia uptake in our case. The $\mathrm{NH}_{3}$ uptake capacity of JCM-1 $\left(\mathbf{C l}^{-}\right)$was increased, although its $\mathrm{N}_{2}$ adsorption behavior was almost the same (Fig. 3). Because of high porosity of JCM-1 and the weaker interaction with nitrogen compared to ammonia, the anion exchange effect on the nitrogen adsorption properties of JCM-1 and JCM-1 $\left(\mathbf{C l}^{-}\right)$is less pronounced compared to the ammonia adsorption. At 1 bar, JCM-1 $\left(\mathbf{C l}^{-}\right)$adsorbed 11.7 and $7.2 \mathrm{mmol} \mathrm{g}^{-1}$ of $\mathrm{NH}_{3}$ at $273 \mathrm{~K}$ and $298 \mathrm{~K}$, respectively, which increased by $48 \%$ (273 K) and $26 \%$ (298 K), compared with JCM-1 (Fig. 5). The crystallinity and porosity of JCM-1 $\left(\mathbf{C l}^{-}\right)$were well retained after $\mathrm{NH}_{3}$ adsorption, as confirmed by PXRD and $\mathrm{N}_{2}$ adsorption data (Fig. 3). In the cycling experiment, JCM-1( $\left.\mathbf{C l}^{-}\right)$showed gradually decreasing $\mathrm{NH}_{3}$ capacity after the first cycle (Fig. $4 \mathrm{~b}$ and d), which means that the sample was not fully activated at room temperature. Activation of the sample after the $5^{\text {th }}$ cycle at an elevated
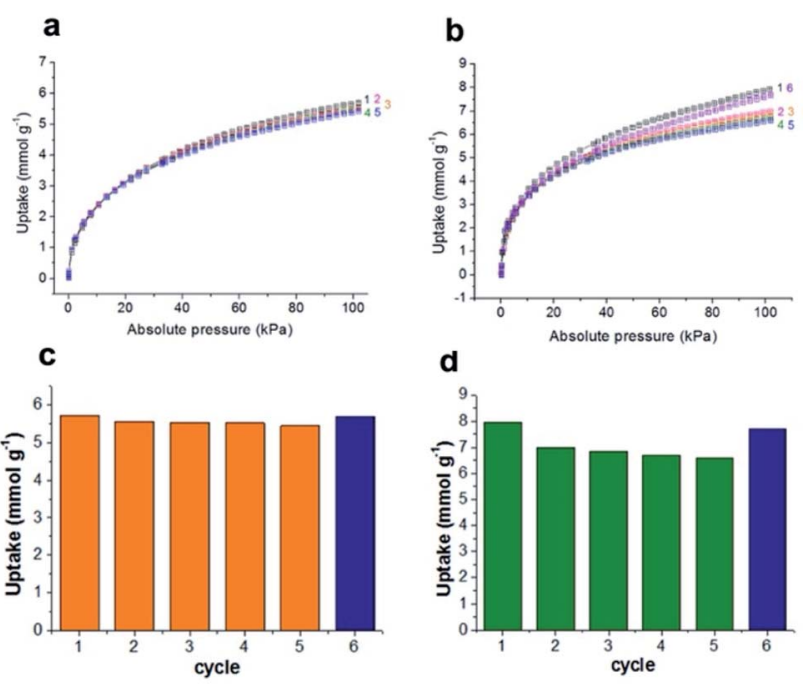

Fig. 4 Adsorption isotherms of (a) repeated $\mathrm{NH}_{3}$ adsorption cycles in JCM-1 and (b) JCM-1(Cl-) at ambient conditions (298 K and 1 bar) uptake capacity of (c) repeated $\mathrm{NH}_{3}$ adsorption cycles in JCM-1 and (d) $\mathrm{JCM}-1\left(\mathrm{Cl}^{-}\right)$at ambient conditions (298 $\mathrm{K}$ and 1 bar).

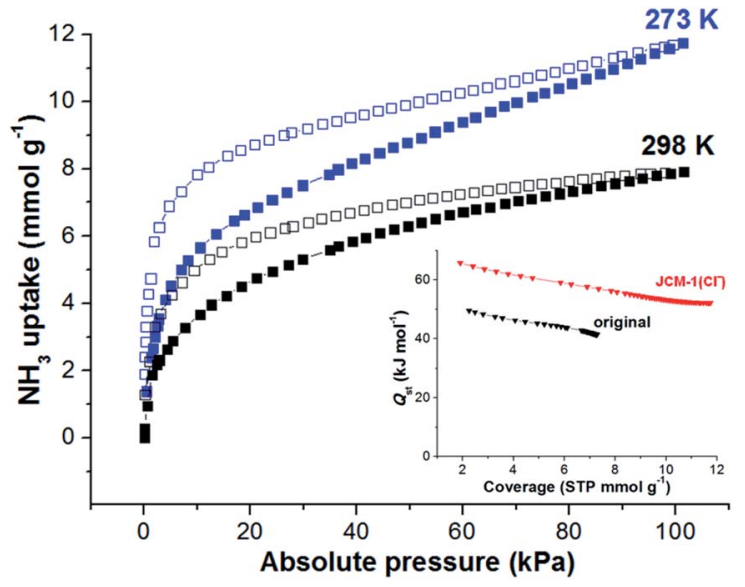

Fig. $5 \mathrm{NH}_{3}$ adsorption isotherms of $\mathrm{JCM}-1\left(\mathrm{Cl}^{-}\right)$at $273 \mathrm{~K}$ and $298 \mathrm{~K}$. Inset: isosteric heat of sorption $\left(Q_{\mathrm{st}}\right)$ of $\mathrm{NH}_{3}$ in $\mathrm{JCM}-1$ and $\mathrm{JCM}-1\left(\mathrm{Cl}^{-}\right)$.

temperature of $358 \mathrm{~K}$ for $5 \mathrm{~h}$ regenerated $\mathbf{J C M - 1}\left(\mathbf{C l}^{-}\right)$and the initial $\mathrm{NH}_{3}$ uptake capacity of was almost recovered (Fig. 4d).

The isosteric heats $\left(Q_{\text {st }}\right)$ of adsorption for $\mathrm{NH}_{3}$ within JCM-1 or JCM-1 $\left(\mathbf{C l}^{-}\right)$was calculated by employing the Virial method. ${ }^{\mathbf{4 1}}$ Because of the hysteresis in the $\mathrm{NH}_{3}$ adsorption isotherms, we calculated the $Q_{\text {st }}$ values using the desorption curves, which is also valid for explaining the change in the regeneration temperatures. ${ }^{\mathbf{4 2 - 4 4}}$ The $Q_{\text {st }}$ values for $\mathrm{NH}_{3}$ desorption in JCM$\mathbf{1}\left(\mathbf{C l}^{-}\right)$were higher by ca. $20 \mathrm{~kJ} \mathrm{~mol}^{-1}$ than JCM-1 in all coverages (inset in Fig. 5). The higher $Q_{\text {st }}$ value of $\mathbf{J C M - 1}\left(\mathbf{C l}^{-}\right)$supports the reason for the increased regeneration temperature after ion substitution. The enhanced $\mathrm{NH}_{3}$ affinity of JCM-1(Cl$\left.{ }^{-}\right)$could be confirmed using density functional theory (DFT) calculations. For DFT calculations, the appropriate structural models of each framework were prepared using the crystal structures of JCM-1 and $\mathbf{J C M - 1}\left(\mathbf{C l}^{-}\right)$. The initial coordinate of $\mathrm{NH}_{3}$ was loaded into each model structure, followed by further geometry optimization (see the ESI $\dagger$ ). The $\mathrm{NH}_{3}$ molecule showed stronger interaction with the imidazolium- $\mathrm{Cl}^{-}$pair than the imidazolium$\mathrm{NO}_{3}{ }^{-}$in the optimized structures, as the interaction enthalpies of JCM-1 and JCM-1 $\left(\mathbf{C l}^{-}\right)$with $\mathrm{NH}_{3}$ molecule were calculated to be $20.8 \mathrm{~kJ} \mathrm{~mol}^{-1}$ and $50.0 \mathrm{~kJ} \mathrm{~mol}^{-1}$, respectively (Fig. S3 and $\left.\mathrm{S} 4{ }^{\dagger}\right)$, which is qualitatively following the experimental observations.

\section{Mechanism of ammonia adsorption on JCM-1 and JCM-1( $\left.\mathrm{Cl}^{-}\right)$}

A simple interpretation of the above observation is that the adsorbed $\mathrm{NH}_{3}$ molecule interacts more strongly with $\mathrm{Cl}^{-}$than $\mathrm{NO}_{3}{ }^{-}$ions. Contrary to this expectation, DFT calculations revealed a more delicate interplay between $\mathrm{NH}_{3}$ and the imidazolium-anion pairs. Before $\mathrm{NH}_{3}$ loading, $\mathrm{NO}_{3}{ }^{-}$or $\mathrm{Cl}^{-}$is engaged in hydrogen bonding with the imidazolium in the framework. The distance between $\mathrm{NO}_{3}{ }^{-}$and imidazolium proton is $1.93 \AA$, whereas the distance between $\mathrm{Cl}^{-}$and imidazolium proton is $2.21 \AA$ (Fig. S5 $\dagger$ ). Upon adsorption, $\mathrm{NH}_{3}$ molecules have to compete with the anions to form hydrogen bonding with the imidazolium proton. As expected, in the optimized structures of the $\mathrm{NH}_{3}$-loaded JCM-1 and JCM-1(Cl $\left.{ }^{-}\right)$, 
a

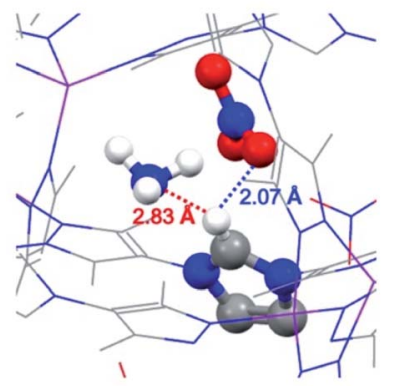

b

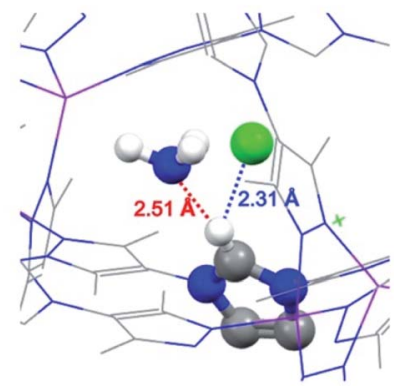

Fig. $6 \mathrm{NH}_{3}$-loaded optimized structures of (a) JCM-1 and (b) JCM$1\left(\mathrm{Cl}^{-}\right)$.

the distances between the anion and imidazolium proton increased (Fig. 5). On the other hand, a weak hydrogen bond between an $\mathrm{NH}_{3}$ molecule and the imidazolium proton was detected. In the $\mathrm{NH}_{3} @ \mathbf{J C M}-\mathbf{1}$, the distance between the nitrogen atom of $\mathrm{NH}_{3}$ and the imidazolium proton was $2.83 \AA$ (Fig. 6a). Interestingly, in the $\mathrm{NH}_{3} @ \mathbf{J C M}-\mathbf{1}\left(\mathbf{C l}^{-}\right)$, the distance was $2.51 \AA$, which is significantly shorter than that of JCM-1 and explains why JCM-1 $\left(\mathbf{C l}^{-}\right)$exhibits the enhanced $\mathrm{NH}_{3}$ affinity (Fig. 6b). As above mentioned, this interaction is similar to that for imidazolium-based ionic liquids having high ammonia solubility. ${ }^{35-38}$

The interaction between $\mathrm{NH}_{3}$ and the imidazolium group on the pore surface was experimentally observed by IR spectroscopy (Fig. S6 $\dagger$ ). We measured the IR spectra of the frameworks before and after exposure to $\mathrm{NH}_{3}$ gas. In both structures, imidazolium C-H stretching bands ${ }^{45}\left(2900-3100 \mathrm{~cm}^{-1}\right)$ were slightly broadened and blue-shifted after exposure to the $\mathrm{NH}_{3}$ atmosphere. $^{\mathbf{4 0 , 4 6}}$ The band-broadening and band-shift are indicative of the formation of the weak hydrogen bond between imidazolium and the $\mathrm{NH}_{3}$ molecule, which is coincident with the DFT calculation results.

Dynamic breakthrough curves were obtained under dry and humid conditions ( $0 \%$ relative humidity $(\mathrm{RH})$ and $80 \% \mathrm{RH})$ at a feed concentration of $1000 \mathrm{ppm} \mathrm{NH}_{3}$ and a temperature of 298 $\mathrm{K}$. We observed the increase in the adsorption amount of ammonia in $\mathbf{J C M - 1}\left(\mathbf{C l}^{-}\right)$in both humid and wet conditions, which shows the same tendency with the adsorption isotherms, while JCM-1 adsorbs only dry ammonia (Fig. S7-S10†).

\section{Conclusions}

In conclusion, we report JCM-1 which can adsorb a high amount of $\mathrm{NH}_{3}$ at an ambient condition without structural deformation. JCM-1 is recyclable even at room temperature through the weak interaction between $\mathrm{NH}_{3}$ and imidazolium functionalities by mimicking ionic liquids. Furthermore, we demonstrated the control of the $\mathrm{NH}_{3}$ sorption property of JCM-1 by simple ion substitution in a post-synthetic manner. After exchanging the anion from nitrate to chloride, the affinity of MOF toward $\mathrm{NH}_{3}$ was enhanced resulting in the increase in the uptake capacity while the regenerability was slightly decreased.

This work suggests a new potential application of imidazoliumbased MOFs for ammonia capture, as well as the effect of the anion species for ammonia adsorption in ionic porous materials.

\section{Experimental}

\section{Materials and methods}

All the reagents and solvents were commercially available and used as supplied without further purification. Elemental analysis (EA) for $\mathrm{C}, \mathrm{H}$, and $\mathrm{N}$ were carried out using Flash 2000 (Thermo Fisher Scientific Inc.). FT-IR measurements were processed in Bruker ALPHA FT-IR spectrometer. Single crystal X-ray diffraction (SXRD) analysis was carried out at synchrotron radiation of 2D-SMC and 6D-C\&S UNIST-PAL (crystallography) at the Pohang Accelerator Laboratory (PAL, Korea). The powder XRD diffraction patterns were obtained on a Rigaku Smartlab system equipped with $\mathrm{Cu}$ sealed tube. Thermogravimetric analysis (TGA) were measured under $\mathrm{N}_{2}$ atmosphere with a PerkinElmer Pyris. All gas sorption isotherms were measured with BELSORP-max volumetric adsorption equipment. Purified compounds were further dried under high vacuum (0.01-0.05 Torr).

\section{MOF synthesis}

JCM-1 ([Co(PzIm) $\left.\left(\mathrm{NO}_{3}\right)\right], \mathrm{H}_{2}$ PzIm $=$ 1,3-bis(3,5-dimethyl-1 $H_{\text {- }}$ pyrazol-4-yl)-1 $H$-imidazol-3-ium) and JCM-1(C) $\left.{ }^{-}\right)$([Co(P$\mathrm{zIm})(\mathrm{Cl})]$ ) was synthesized following our previously reported methods. ${ }^{31}$

Synthesis of JCM-1. $\mathrm{Co}\left(\mathrm{NO}_{3}\right)_{2} \cdot 6 \mathrm{H}_{2} \mathrm{O}(0.075 \mathrm{mmol}, 21.9 \mathrm{mg})$ and $\mathrm{H}_{2} \mathrm{PzImCl}(0.025 \mathrm{mmol}, 7.3 \mathrm{mg}$ ) were dissolved in $0.5 \mathrm{~mL}$ of $\mathrm{DMF}$ in a $4 \mathrm{~mL}$ vial. The vial was stand in an oven at $120^{\circ} \mathrm{C}$ for 3 days to yield purple single crystals. The crystals were washed with water and DMF several times, followed by solvent exchange to methanol. Then, the crystals were activated under high vacuum at $393 \mathrm{~K}$ to afford JCM-1 $\left(\left[\mathrm{Co}(\mathrm{PzIm})\left(\mathrm{NO}_{3}\right)\right]\right)$. Elemental analysis data: anal. calcd for $\left(\mathrm{C}_{13} \mathrm{H}_{15} \mathrm{CoN}_{7} \mathrm{O}_{3}\right)\left(\mathrm{H}_{2} \mathrm{O}\right)_{3.5}$ : C, 35.54; H, 5.05; N, 22.32. Found: C, 35.31; H, 4.87; N, 22.32.

Synthesis of JCM-1 $\left(\mathbf{C l}^{-}\right)$. The as-synthesized JCM-1 powder was shaken in methanolic solution of $1 \mathrm{M} \mathrm{LiCl}$. The solution was exchanged once a day for a week, followed by washing with fresh methanol to afford the product $\mathbf{J C M - 1}\left(\mathbf{C l}^{-}\right)$. It is noteworthy that the exchange process was carried out longer (7 days) than before ( 3 days) for the full ion substitution. After anion exchange, the product was washed with fresh methanol several times and dried under high vacuum at $373 \mathrm{~K}$. In addition to the previously reported FT-IR, PXRD and EDS analysis, the fully exchanged product was further confirmed by elemental analysis and single-crystal XRD analysis. Elemental analysis data of JCM$\mathbf{1}\left(\mathrm{Cl}^{-}\right)$: anal. calcd for $\left(\mathrm{C}_{13} \mathrm{H}_{15} \mathrm{CoN}_{6}\right) \mathrm{Cl}_{1}\left(\mathrm{H}_{2} \mathrm{O}\right)_{2}$ : C, 40.48; $\mathrm{H}$, 4.97; N, 21.79. Found: C, 40.15; H, 5.28; N, 21.61.

\section{X-ray crystallographic analysis}

Single crystal X-ray diffraction (SXRD) analysis was carried out at the synchrotron radiation of 2D-SMC at the Pohang Accelerator Laboratory (PAL, Korea). The SXRD patterns of crystals 
coated with paratone oil were collected at $100 \mathrm{~K}$. Using Olex $2,{ }^{47}$ the structures were solved by ShelXT ${ }^{48}$ using Intrinsic Phasing. The crystal structure of $\mathbf{J C M - 1}\left(\mathbf{C l}^{-}\right)$was refined by ShelXL ${ }^{49}$ using least squares minimization. CCDC 1912377 contains the structural information for $\mathbf{J C M - 1}\left(\mathbf{C l}^{-}\right)$.

\section{Gas sorption experiments}

Repeated $\mathbf{N H}_{3}$ sorption using JCM-1. The activation/ adsorption cycle was repeated over five times. Between each cycle, samples were activated at room temperature for 10 hours under dynamic vacuum. The $\mathrm{NH}_{3}$ uptake patterns were well retained with negligible decrease in uptake capacity. The initial $\mathrm{NH}_{3}$ adsorption capacity was fully restored after activating at a higher temperature.

Repeated $\mathbf{N H}_{3}$ sorption using $\mathbf{J C M}-\mathbf{1}\left(\mathbf{C l}^{-}\right)$. The activation/ adsorption cycle of $\mathbf{J C M - 1}\left(\mathbf{C l}^{-}\right)$was repeated over five times. Between each cycle, samples were activated at room temperature under dynamic vacuum for $10 \mathrm{~h}$. The $\mathrm{NH}_{3}$ uptake capacity was decreased after the $1^{\text {st }}$ cycle, which means the $\mathrm{NH}_{3}$ was not fully detached from the framework. Interestingly, in the rest of the cycle, the adsorption capacity was no longer significantly decreased. When regenerated at a higher temperature, the initial $\mathrm{NH}_{3}$ adsorption capacity was recovered. It means that the capacity decrease in the cycle experiment was due to the enhanced affinity of the framework with $\mathrm{NH}_{3}$ gas, not due to the collapse of the framework.

\section{Isosteric heat of sorption}

The isosteric heat of sorption $Q_{\mathrm{st}}$ was calculated using the virial type expression to fit the isotherms of $273 \mathrm{~K}$ and $298 \mathrm{~K}^{\mathbf{5 0}}$

$$
\ln P=\ln N+1 / T \sum_{i=0}^{m} a_{i} N^{i}+\sum_{i=0}^{n} b_{i} N^{i}
$$

where $P$ is the pressure of the gas phase at equilibrium (bar), $N$ is the adsorbed amount per mass of adsorbent $\left(\mathrm{mmol} \mathrm{g}^{-1}\right), T$ is the absolute temperature, $a_{i}$ and $b_{i}$ are virial coefficients, and $m$ and $n$ are numbers of coefficients used to describe the isotherms.

$$
Q_{\mathrm{st}}=-R \sum_{i=0}^{m} a_{i} N^{i}
$$

Then, with the virial coefficient $\left(a_{i}\right)$ and the following equation, the coverage-dependent isosteric heat of sorption was calculated. $R$ is the universal gas constant.

\section{DFT calculations}

Both geometry optimizations and frequency calculations were performed using Gaussian 09 using B3LYP/6-31G(d,p) basis set. ${ }^{51}$ In the geometry optimization, the default tight convergence in the SCF cycle was used without any orbital symmetry constraints. For the calculation of MOFs, model structures were generated with appropriate pore structure based on crystallography data. Two-layer ONIOM method ${ }^{52}$ was used with B3LYP/6$31 \mathrm{G}(\mathrm{d}, \mathrm{p})$ basis set for high level, and molecular mechanics using UFF force field ${ }^{53}$ for low level. Coordinates of the rigid cationic framework of MOF structures (JCM-1 and JCM-1(Cl $\left.{ }^{-}\right)$) were fixed according to the crystallography data, while the geometry of anions $\left(\mathrm{NO}_{3}{ }^{-}\right.$or $\left.\mathrm{Cl}^{-}\right)$and ammonia molecule were optimized during the calculation. High level model systems in ONIOM calculation were selected as one imidazolium and its counter anions $\left(\mathrm{NO}_{3}{ }^{-}\right.$or $\left.\mathrm{Cl}^{-}\right)$with an ammonia molecule. The interaction enthalpies of the framework with the guest molecule were calculated from the difference in total energies for the model structure $\left(H_{\text {interaction }}=H_{\mathrm{MOF}}+H_{\text {guest }}-H_{\mathrm{MOF}}\right.$ with guest $)$.

\section{Breakthrough experiments}

Breakthrough experiments were carried out with a BELCAT-II equipped with a BELMASS mass spectrometer. The pelletized sample was packed in the breakthrough column of $0.5 \mathrm{~cm}$ in width and $1.0 \mathrm{~cm}$ in height and activated at $120^{\circ} \mathrm{C}$ for $10 \mathrm{~h}$ in a He flow. The dry ammonia breakthrough experiments were performed in $1000 \mathrm{ppm} \mathrm{NH}_{3}$ gas balanced with $\mathrm{He}$ at $25^{\circ} \mathrm{C}$. In the case of wet ammonia breakthrough experiments, the sample was pre-saturated with humid (80\% RH) He gas for $5 \mathrm{~h}$ at $25{ }^{\circ} \mathrm{C}$ prior to each measurement. And then, $1000 \mathrm{ppm} \mathrm{NH}_{3}$ gas balanced with humid ( $80 \% \mathrm{RH}) \mathrm{He}$ was introduced to the sample-packed column for $18 \mathrm{~h}$ at $25{ }^{\circ} \mathrm{C}$. The regeneration between consecutive ammonia breakthrough cycles was different to the degassing procedure. The sample was activated with $25{ }^{\circ} \mathrm{C}$ for $10 \mathrm{~h}$ in a He flow. The effluent gas signal was continuously monitored by the BELMASS mass spectrometer. The amount of adsorbed $\mathrm{NH}_{3}$ was calculated by the integration of the breakthrough curve with ChemMaster program. The total gas flow was set at $30 \mathrm{sccm}$ in all cases.

In the case of dry ammonia breakthrough experiments, the amount of adsorbed ammonia in the breakthrough curve was calculated through the ChemMaster program by integrating the hatched area which is the gap between the elute curves of the saturated ammonia in the blank and the sample. The weight of glass beads in blank test (or the weight of the sample in breakthrough curve) was measured by comparing empty column weight and weight of column with beads (or sample) after activation. The calibration factor (count per mmol) of dry 1000 ppm breakthrough test was calculated with the ChemMaster program by choosing the flat region of blank test after $\mathrm{NH}_{3}$ fully was eluted.

In the case of wet ammonia breakthrough experiments, the ammonia breakthrough curves after pre-humidification for $5 \mathrm{~h}$ were depicted. The amount of adsorbed ammonia in the breakthrough curve at $80 \% \mathrm{RH}$ and $1000 \mathrm{ppm}$ was calculated by the ChemMaster program by integrating the hatched area which is the gap between the elute curves of saturated ammonia in the blank and the sample. The weight of glass beads in the blank test (or the weight of the sample in the breakthrough) was measured by comparing empty column weight and weight of column with beads (or sample) after activation. The calibration factor (count per mmol) of the breakthrough test at $80 \% \mathrm{RH}$ and 1000 ppm was calculated by choosing the flat region of the blank test after $\mathrm{NH}_{3}$ was fully eluted. It should be noted that the ammonia breakthrough curve at dry $1000 \mathrm{ppm}$ and that at $80 \%$ $\mathrm{RH}$ and $1000 \mathrm{ppm}$ were not compatible in retention time 
because two have distinct blank breakthrough curves and so the calibration factors.

\section{Conflicts of interest}

There are no conflicts to declare.

\section{Acknowledgements}

This work was supported by Institute for Basic Science (IBS) [IBSR007-D1]. National Research Foundation of Korea (NRF) grant funded by the Korean government (MSIP: Ministry of Science, ICT and Future Planning) (No. NRF2016H1A2A1908350 - Global PhD Fellowship Program). The X-ray crystallography analysis was performed at the Pohang Accelerator Laboratory (PLS-II BL2D SMC and 6D C\&S Unist-PAL beamline). D.-W Lim acknowledges the support from the ACCEL program, Japan Science and Technology Agency (JST), JPMJAC1501. We thank Prof. S. S. Park for helpful discussion.

\section{Notes and references}

1 NITROGEN (FIXED)—ammonia, U.S. Geological Survey, Mineral Commodity Summaries, 2018, pp. 116-117, https://minerals.usgs.gov/minerals/pubs/commodity/ nitrogen/mcs-2018-nitro.pdf.

2 M. Sharma, S. Kishore, S. N. Tripathi and S. N. Behera, J. Atmos. Chem., 2007, 58, 1-17.

3 L. Gong, R. Lewicki, R. J. Griffin, F. K. Tittel, C. R. Lonsdale, R. G. Stevens, J. R. Pierce, Q. G. J. Malloy, S. A. Travis, L. M. Bobmanuel, B. L. Lefer and J. H. Flynn, Atmos. Environ., 2013, 77, 893-900.

4 Y. Wu, B. Gu, J. W. Erisman, S. Reis, Y. Fang, X. Lu and X. Zhang, Environ. Pollut., 2016, 218, 86-94.

5 D. Britt, D. Tranchemontagne and O. M. Yaghi, Proc. Natl. Acad. Sci. U. S. A., 2008, 105, 11623-11627.

6 O. T. Wilcox, A. Fateeva, A. P. Katsoulidis, M. W. Smith, C. A. Stone and M. J. Rosseinsky, Chem. Commun., 2015, 51, 14989-14991.

7 M. J. Katz, A. J. Howarth, P. Z. Moghadam, J. B. DeCoste, R. Q. Snurr, J. T. Hupp and O. K. Farha, Dalton Trans., 2016, 45, 4150-4153.

8 Y. Chen, X. Zhang, K. Ma, Z. Chen, X. Wang, J. Knapp, S. Alayoglu, F. Wang, Q. Xia, Z. Li, T. Islamoglu and O. K. Farha, ACS Appl. Nano Mater., 2019, 2, 6098-6102.

9 S. Moribe, Z. Chen, S. Alayoglu, Z. H. Syed, T. Islamoglu and O. K. Farha, ACS Mater. Lett., 2019, 1, 476-480.

10 Y. Zhang, X. Zhang, Z. Chen, K. Ichi Otake, G. W. Peterson, Y. Chen, X. Wang, L. R. Redfern, S. Goswami, P. Li, T. Islamoglu, B. Wang and O. K. Farha, ChemSusChem, 2020, 13, 1710-1714.

11 D. W. Kim, D. W. Kang, M. Kang, J.-H. Lee, J. H. Choe, Y. S. Chae, D. S. Choi, H. Yun and C. S. Hong, Angew. Chem., Int. Ed., 2020, 59, 22531-22536.

12 E. Binaeian, Y. Li, H.-A. Tayebi and D. Yuan, J. Hazard. Mater., 2021, 416, 125933.
13 X. Han, W. Lu, Y. Chen, I. Silva, J. Li, L. Lin, W. Li, A. M. Sheveleva, H. G. W. Godfrey, Z. Lu, F. Tuna, E. J. L. Mcinnes, Y. Cheng, L. L. Daemen, L. J. M. McPherson, S. J. Teat, M. D. Frogley, S. Rudic, P. Manuel, A. J. Ramirez-cuesta, S. Yang and M. Schröder, J. Am. Chem. Soc., 2021, 143, 3153-3161.

14 C. Marsh, X. Han, J. Li, Z. Lu, S. P. Argent, I. da Silva, Y. Cheng, L. L. Daemen, A. J. Ramirez-Cuesta, S. P. Thompson, A. J. Blake, S. Yang and M. Schröder, J. Am. Chem. Soc., 2021, 143, 6586-6592.

15 M. K. Matikolaei and E. Binaeian, ACS Appl. Mater. Interfaces, 2021, 13, 27159-27168.

16 L. Li, Y. Wang, J. Yang, Y. Chen and J. Li, ChemPlusChem, 2016, 81, 222-228.

17 A. J. Rieth and M. Dinca, J. Am. Chem. Soc., 2018, 140, 34613466.

18 A. J. Rieth, Y. Tulchinsky and M. Dinca, J. Am. Chem. Soc., 2016, 138, 9401-9404.

19 K. Vikrant, V. Kumar, K.-H. Kim and D. Kukkar, J. Mater. Chem. A, 2017, 5, 22877-22896.

20 B. Xiao, P. S. Wheatley, X. Zhao, A. J. Fletcher, S. Fox, A. G. Rossi, I. L. Megson, S. Bordiga, L. Regli, K. M. Thomas and R. E. Morris, J. Am. Chem. Soc., 2007, 129, 1203-1209.

21 G. W. Peterson, J. J. Mahle, J. B. DeCoste, W. O. Gordon and J. A. Rossin, Angew. Chem., Int. Ed., 2016, 55, 6235-6238.

22 X. Han, H. G. W. Godfrey, L. Briggs, A. J. Davies, Y. Cheng, L. L. Daemen, A. M. Sheveleva, F. Tuna, E. J. L. McInnes, J. Sun, C. Drathen, M. W. George, A. J. Ramirez-Cuesta, K. M. Thomas, S. Yang and M. Schröder, Nat. Mater., 2018, 17, 691-696.

23 J. Yang, B. Du, J. Liu, R. Krishna, F. Zhang, W. Zhou, Y. Wang, J. Li and B. Chen, Chem. Commun., 2018, 54, 14061-14064.

24 M. Savage, Y. Cheng, T. L. Easun, J. E. Eyley, S. P. Argent, M. R. Warren, W. Lewis, C. Murray, C. C. Tang, M. D. Frogley, R. T. Murden, M. J. Benham, A. N. Fitch, A. J. Blake, A. J. Ramirez-Cuesta, S. Yang and M. Schröder, Adv. Mater., 2016, 28, 8705-8711.

25 L. M. Rodriguez-Albelo, E. Lopez-Maya, S. Hamad, A. R. RuizSalvador, S. Calero and J. A. Navarro, Nat. Commun., 2017, 8, 14457.

26 J. H. Carter, X. Han, F. Y. Moreau, I. Silva, A. Nevin, H. G. W. Godfrey, C. C. Tang, S. H. Yang and M. Schröder, J. Am. Chem. Soc., 2018, 140, 15564-15567.

27 J. B. DeCoste and G. W. Peterson, Chem. Rev., 2014, 114, 5695-5727.

28 N. S. Bobbitt, M. L. Mendonca, A. J. Howarth, T. Islamoglu, J. T. Hupp, O. K. Farha and R. Q. Snurr, Chem. Soc. Rev., 2017, 46, 3357-3385.

29 H. G. W. Godfrey, I. da Silva, L. Briggs, J. H. Carter, C. G. Morris, M. Savage, T. L. Easun, P. Manuel, C. A. Murray, C. C. Tang, M. D. Frogley, G. Cinque, S. Yang and M. Schröder, Angew. Chem., Int. Ed., 2018, 57, 1477814781.

30 C. Petit and T. J. Bandosz, Adv. Funct. Mater., 2010, 20, 111118. 
31 J. Lee, C. Y. Chuah, J. Kim, Y. Kim, N. Ko, Y. Seo, K. Kim, T. H. Bae and E. Lee, Angew. Chem., Int. Ed., 2018, 57, 7869-7873.

32 J. G. Duan, W. Q. Jin and S. Kitagawa, Coord. Chem. Rev., 2017, 332, 48-74.

33 K. Wang, X.-L. Lv, D. Feng, J. Li, S. Chen, J. Sun, L. Song, Y. Xie, J.-R. Li and H.-C. Zhou, J. Am. Chem. Soc., 2016, 138, 914-919.

34 N. C. Burtch, H. Jasuja and K. S. Walton, Chem. Rev., 2014, 114, 10575-10612.

35 A. Yokozeki and M. B. Shiflett, Appl. Energy, 2007, 84, 12581273.

36 A. Yokozeki and M. B. Shiflett, Ind. Eng. Chem. Res., 2007, 46, 1605-1610.

37 G. Li, Q. Zhou, X. Zhang, L. Wang, S. Zhang and J. Li, Fluid Phase Equilib., 2010, 297, 34-39.

38 K. N. Ruckart, Y. Zhang, W. M. Reichert, G. W. Peterson and T. G. Ind, Ind. Eng. Chem. Res., 2016, 55, 12191-12204.

39 T. Kajiwara, M. Higuchi, D. Watanabe, H. Higashimura, T. Yamada and H. Kitagawa, Chem.-Eur. J., 2014, 20, 15611-15617.

40 D. Saha and S. Deng, J. Colloid Interface Sci., 2010, 348, 615620.

41 H. Furukawa, M. A. Miller and O. M. Yaghi, J. Mater. Chem., 2007, 17, 3197-3204.
42 K. J. Chang and O. Talu, Appl. Therm. Eng., 1996, 16, 359-374. 43 D. Ma, J. Zhang, J. Bai and H. Zhang, Nat. Resour., 2014, 5, 782-794.

44 J. A. Mason, M. Veenstra and J. R. Long, Chem. Sci., 2014, 5, 32-51.

45 S. Cha, M. Ao, W. Sung, B. Moon, B. Ahlstrom, P. Johansson, Y. Ouchi and D. Kim, Phys. Chem. Chem. Phys., 2014, 16, 9591-9601.

46 J. Joseph and E. D. Jemmis, J. Am. Chem. Soc., 2007, 129, 4620-4632.

47 O. V. Dolomanov, L. J. Bourhis, R. J. Gildea, J. A. K. Howard and H. Puschmann, J. Appl. Crystallogr., 2009, 42, 339-341.

48 G. M. Sheldrick, Acta Crystallogr., Sect. A: Found. Adv., 2015, 71, 3-8.

49 G. M. Sheldrick, Acta Crystallogr., Sect. C: Struct. Chem., 2015, 71, 3-8.

50 H. Furukawa, M. A. Miller and O. M. Yaghi, J. Mater. Chem., 2007, 17, 3197.

51 G. M. J. Frischet al., Revision A.02, Gaussian, Inc., Wallingford CT, 2009.

52 S. Dapprich, I. Komáromi, K. S. Byun, K. Morokuma and M. J. Frisch, J. Mol. Struct.: THEOCHEM, 1999, 461-462, 1-21.

53 A. K. Rappe, C. J. Casewit, K. S. Colwell, W. A. Goddard and W. M. Skiff, J. Am. Chem. Soc., 1992, 114, 10024-10035. 